\title{
Inledning \\ Välfärdens utveckling efter 1990-talets kris
}

\author{
ÅKE BERGMARK \& JOHAN FRITZELL
}

Det har nu gått mer än femton år sedan Sverige hamnade i den ekonomiska kris som kännetecknade så stora delar av 1990-talet. Bakgrunden till detta temanummer om välfärden i Sverige under 2000-talet är att vi nu kommit så långt in på det nya millenniet att det finns anledning att ställa sig frågor om hur välfärden och socialpolitiken har förändrats. Är 1990-talets kris numer bara historia eller kan vi spåra konsekvenser i människors välfärd och i de socialpolitiska systemen också idag? Har 1990-talets trender i välfärdens fördelning och institutionella organisering fortsatt eller ej? Vi, författarna av denna inledande text, var under ett par år runt millennieskiftet knutna till den av Joakim Palme ledda svenska Välfärdskommittén, eller Kommittén Välfärdsbokslut som var det formella namnet, vars uppdrag var att utforska välfärdens och socialpolitikens förändringar under 1990-talet. Också många av de övriga författarna i detta temanummer medverkade på olika sätt $\mathrm{i}$ kommitténs arbeten. Det skall på en gång sägas att vi av naturliga skäl inte haft som målsättning att nu inom ramen för detta temanummer i Socialvetenskaplig Tidskrift ge en lika fullständig kartläggning av välfärd och socialpolitik som den vi hade möjlighet att göra i de 14 volymer som Välfärdskommittén publicerade. Istället har vi sökt belysa några områden och forskningsfrågor som vi ser som centrala för välfärden och ofärden i Sverige idag och också ur ett framtidsperspektiv. Tidskriftsformatet innebär dock att det finns andra områden av vikt som vi av utrymmesskäl tvingas utelämna denna gång. Innan vi kort presenterar de artiklar som temanumret innehåller finns det skäl att rekapitulera något av utvecklingen under det föregående decenniet.

\section{Vad var det som hände under 1990-talet?}

Få om ens något av 1900-talets decennier torde i nuläget vara så omskrivna i socialvetenskaperna som 1990-talet. Vad var det då egentligen som hände under krisåren och den period av påfrestningar i de offentliga finanserna som följde? En avgörande skillnad mellan den ekonomiska krisen på 
nittiotalet och tidigare nedgångar i början av sjuttio- och åttiotalen var att krisen i termer av arbetslöshet och ekonomiska svårigheter blev mer kännbar för befolkningen i allmänhet. Under 1990-talets första hälft ökade arbetslösheten till nivåer som inte hade uppmätts sedan trettiotalet, samtidigt som sysselsättningsnivåerna rasade (se Figur 1). Lundborg (2000) menar att vi kan urskilja tre överlappande vågor av arbetslöshet där olika sektorer - och individer - drabbades vid olika faser av krisen. Först slog krisen mot exportindustrin, utöver allt annat påverkades denna sektor förstås särdeles negativt av regeringens försök att försvara kronkursen. Därefter ledde en kraftigt minskad efterfrågan på varor i hemmaindustrin till arbetslöshetskriser i dessa branscher. Allt detta ledde så småningom fram till den statsfinansiella krisen. I syfte att minska budgetunderskotten kom den tredje fasen där sysselsättningen i offentlig sektor minskade dramatiskt. Att dessa vågor följde successivt på varandra är också en förklaring till att krisen fick ett så generellt genomslag i befolkningen. Som framgår av Figur 1 innebar det också att arbetslösheten till en början främst ökade för män medan andelen arbetslösa bland kvinnor märktes tydligast när nedskärningarna i offentlig sektor tog fart. Det är dock viktigt att framhålla att arbetslöshetsuppgången och sysselsättningsnedgången totalt sett slog ungefär lika hårt mot kvinnor och män. Det kan vara värt att också påpeka det som inte skedde: det fanns inga tecken på att

\section{Figur I.}

Sysselsättning och arbetslöshet i Sverige 1990-2000 efter kön.

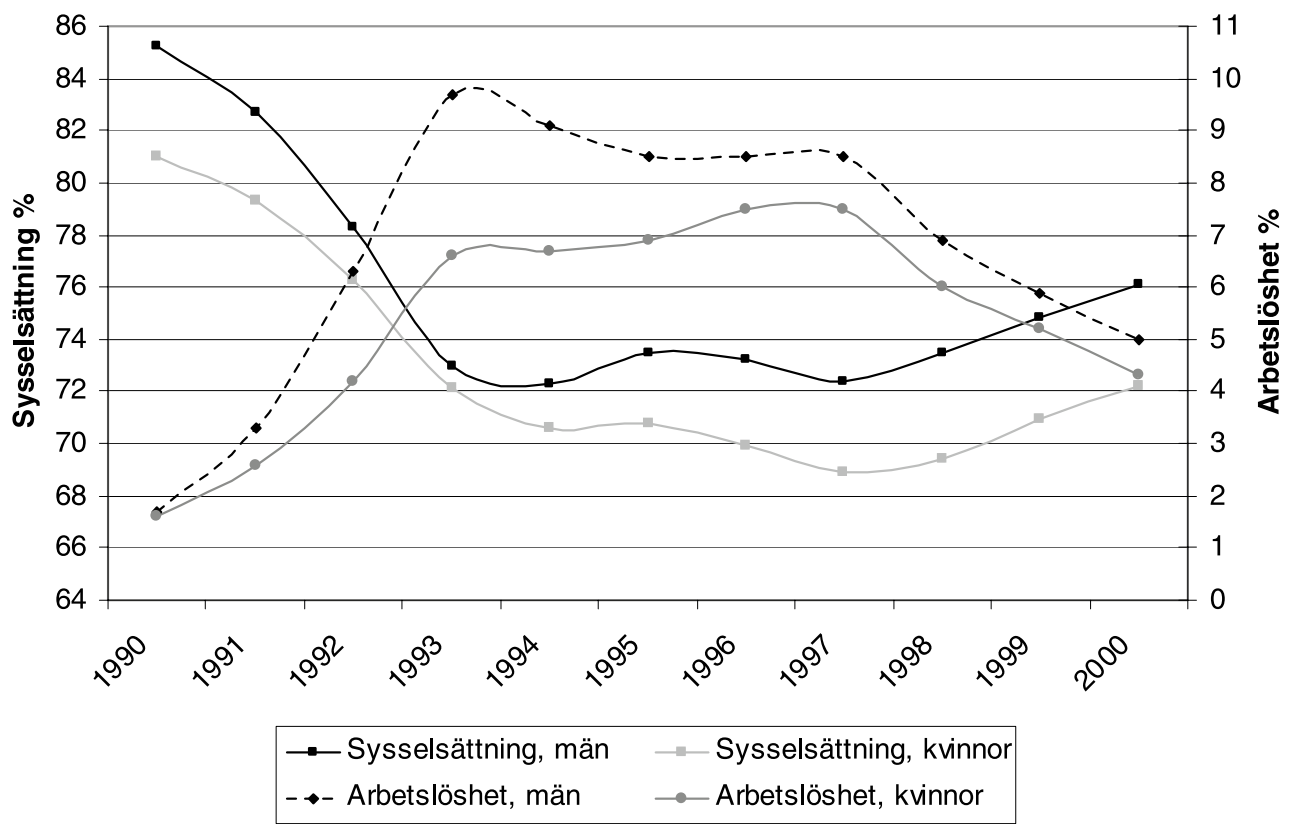


sysselsättningsminskningen resulterade i en tillbakagång till traditionella könsmönster, någon återgång till hemmafruepoken skedde med andra ord inte (Fritzell \& Lundberg 2000).

De dramatiska förändringarna på arbetsmarknaden påverkade naturligtvis även befolkningens ekonomiska situation. Under första halvan av 1990-talet sjönk befolkningens genomsnittsinkomster kraftigt. Inkomstspridningen var trots det relativt konstant under decenniets första hälft. När genomsnittsinkomsternaåterigen steg under decenniets andra hälft ökade också inkomstspridningen, främst till följd av en ökning $i$ toppen av inkomstfördelningen (Fritzell 2001). Detta var en effekt dels av att chefslönebonusen blev påtagligt större, dels av den kraftiga börsuppgången i slutet av decenniet som genererade stora kapitalinkomster.

Sett över hela decenniet var medianinkomsten först vid decenniets slut tillbaka vid den nivå som rådde före krisen. Inkomstutvecklingen under 1990-talet skilde sig emellertid avsevärt mellan olika grupper i befolkningen. För ensamstående mödrar med barn var t.ex. den genomsnittliga disponibla hushållsinkomsten per konsumtionsenhet lägre vid periodens slut än vid dess början. Välfärdens åldersfördelning förändrades också i många avseenden påtagligt under decenniet. Mest tydligt kanske detta framgår vad gäller ekonomiska resurser. Inkomsterna sjönk för yngre och steg bland de äldre (Fritzell 2001). Förmögenheterna koncentrerades också $i$ allt högre utsträckning till de äldre. Denna förändrade åldersgradient i ekonomiska resurser är en fortsättning på en mer långsiktig trend i Sverige.
Frågan om välfärdens fördelning ställs förstås på sin spets när de samlade resurserna minskar så påtagligt som de gjorde under 1990-talets första hälft. Även om i stort sett alla befolkningsgrupper drabbades av krisen var det främst tre grupper som i många av Välfärdskommitténs analyser pekades ut som välfärdens förlorare under 1990-talet: Ungdomar, invandrare och ensamstående mödrar. Det finns all anledning att fortsätta följa välfärdsutvecklingen för dessa grupper. En annan förändring under decenniet tycktes vara en ökad omfattning av marginalisering eller exklusion, en djupare ofärd för mer påtagligt utsatta grupper. Ökningen av det långvariga socialbidragstagandet är ett exempel på detta.

När 1990-talet skärskådas utifrån de socialpolitiska systemen är det framförallt begrepp som nedskärningar och resursbrist som kommer på tal. Och förvisso var det så att i stort sett alla välfärdsstatliga institutioner fick se sina sammanlagda resurser krympa när staten skulle komma till rätta med den statsfinansiella krisen. Utvecklingen var dock ingalunda enhetlig, vare sig över tid eller mellan olika fält av socialpolitiken. Även om resurserna krympte så hanterades detta på olika sätt. Inom exempelvis äldreomsorgen fick allt färre hjälp samtidigt som insatserna koncentrerades på de mest vårdbehövande, inom barnomsorgen ökade istället deltagandet men här skedde åtstramningen genom att de ekonomiska och personella resurserna för varje barn minskade påtagligt. Eftersom den svenska välfärdsmodellen setts som urtypen för en specifik modell finns det också skäl att mer övergripande ställa sig frågan om det 
förekom ett mer djupgående modellskifte i Sverige under 1990-talet. När frågan ställs på detta sätt är det inte i första hand frågan om att ersättningsnivåerna sjönk från 90 till 80 procent inom olika socialförsäkringar som blir den mest centrala. Det handlar snarare om underliggande principer såsom universalism eller relationen mellan privat och offentlig service.

Välfärdskommitténs slutsats var att det inte gick att entydigt belägga något modellskifte vare sig på välfärdstjänsternas eller på transfereringarnas områden (se SOU 2001:79, speciellt 3.6). Den slutsatsen bör dock modifieras genom att det onekligen genomfördes förändringar som också var av principiell natur. Vidare är det viktigt att komma ihåg att också relativt små förändringar i socialpolitiska system, som tagna var för sig knappast kan sägas vara principiella brott, på sikt kan leda till mer långtgående förändringar. Också relativt marginella sänkningar av ersättningsnivåer kan framförallt för välbeställda leda till ökat intresse för individuella lösningar, något som i förlängningen leder till att dessa grupper inte längre vill stödja de offentligt finansierade systemen. Detta kommer i sin tur ytterligare att erodera kvaliteten i dessa system. På så vis kan små förändringar ge upphov till kausala kedjor som leder till ett mer omfattande systemskifte (Hinrichs \& Kangas 2003).

\section{0-talets arv och 2000-talets utmaningar}

Med 1990-talets kris bröts en lång period av en i det närmaste oavbruten expansion av de trygghetssystem som utvecklats inom ramen för den svenska välfärdspolitiken. Ekonomiskt har Sverige hämtat sig väl från det föregående decenniets påfrestningar, men på vissa områden har individuell välfärd och grundläggande försörjningsvillkor inte återställts. Mest grundläggande här är givetvis arbetslösheten och arbetskraftsdeltagandet, där vi trots en mycket gynnsam konjunkturutveckling under ett flertal år inte lyckats nå de nivåer som förelåg före krisen. Ett annat område är socialbidragstagandet, där andelen hushåll som mer stadigvarande är beroende av bidrag för sin försörjning etablerats på högre nivåer än tidigare.

Vid sidan av de konsekvenser som 1990talets utveckling har haft, bestäms förutsättningarna för den framtida välfärdspolitiken i ett samspel mellan en mängd olika faktorer. Den ekonomiska utvecklingen är redan nämnd, men därutöver har sådant som demografi, hälsoutveckling, institutionella förändringar samt politikens utveckling - nationellt och internationellt - betydelse för vilka utmaningar välfärdssystemen ställs inför och vilka lösningar som blir möjliga.

En av de mest avgörande frågorna inför framtiden är hur behov och efterfrågan av offentliga finansiella stöd och välfärdstjänster kan komma att utvecklas. Med utgångspunkt från, relativt säkra, förutsägelser om den demografiska utvecklingen kan jämförelsevis pålitliga prognoser formuleras för områden som äldrevård och hälso- och sjukvård. Dessa prognoser kan sedan korrigeras åt olika håll genom antaganden om hur dödligheten i riket och de äldres hälsa utvecklas, liksom utvecklingen 
av läkemedel och medicinsk teknik. Sveriges befolkning är idag en av världens äldsta. Enligt SCB:s befolkningsprognos kommer också andelen äldre invånare på lång sikt att fortsätta att öka, särskilt i takt med att den stora 40-talistgenerationen når pensionsåldern och därefter rör sig uppåt i åldersklasserna. Oavsett hur de äldres hälsosituation utvecklas, kommer detta att resultera i ett ökat behov av insatser för de äldre (Batljan \& Lagergren 2005), men ökningstakten är samtidigt mycket olika beroende på vilka antaganden som görs i prognoser av detta slag (Batljan 2007).

Framtida befolkningsförändringar påverkar inte bara efterfrågan av olika välfärdstjänster, utan har också stor betydelse för den makroekonomiska utvecklingen och möjligheterna att finansiera de socialpolitiska systemen. Med en krympande förvärvsaktiv befolkning och ett växande antal medborgare som passerar pensionsstrecket riskerar statens finanser att urholkas från såväl utgifts- som inkomstsidan. Under senare år har forskningen om åldrandets effekter på samhällsekonomi och offentliga finanser intensifierats (Malmberg \& Lindh 2000, Institute for Futures Studies 2006). Resultaten från dessa studier har stimulerat till debatt om i vilken utsträckning det är möjligt respektive önskvärt att via arbetskraftsinvandring eller högre födelsetal motverka effekterna av åldrandet. Ett annat alternativ som diskuterats är möjligheterna att öka den reella försörjningskvoten genom att öka antalet sysselsatta och deras arbetstid, bl.a. genom generella arbetsmarknadsåtgärder eller stimulans för äldre att fortsätta förvärvsarbeta efter 65-årsdagen. Om ingen av dessa strategier är möjliga eller fram- gångsrika aktualiseras nedskärningar i form av minskad generositet $i$ transfereringar eller reducering av välfärdstjänsternas kvalitet respektive tillgänglighet. Om statens finanser försämras på det sätt som förutspås i många prognoser kommer sannolikt frågan om prioriteringar mellan olika sektorer och verksamheter att ställas på sin spets.

Utvecklingen på arbetsmarknaden är otvivelaktigt en av de viktigaste frågorna för den framtida välfärdsutvecklingen. Efter 1990-talets krisår sjönk den öppna arbetslösheten kraftigt, för att återigen stiga åren 2003-2005. I dagsläget ser vi dock en ökande sysselsättning och en relativt snabbt sjunkande arbetslöshet. Samtidigt kan vi konstatera att vi befinner oss i en mycket stark högkonjunktur och att arbetsmarknadens utveckling på längre sikt är oerhört svår att förutse. En faktor av vikt här är vilka sektorsvisa förskjutningar som sker. Under det föregående decenniet passerade den privata tjänstesektorn tillverkningsindustrin sett till antalet anställda.

En trend som var tydlig under det föregående decenniet och som fortsatt under 2000-talets inledande år är att det skydd som olika socialförsäkringar erbjuder successivt urholkas på grund av att allt fler har inkomster över det förmånsgrundande taket. På sikt kan denna utveckling få långtgående konsekvenser för medborgarnas stöd för socialförsäkringen, eftersom allt större grupper på arbetsmarknaden kan komma att få förlita sig på privata försäkringslösningar för att få ett gott inkomstbortfallsskydd. Det oskrivna kontrakt som finns mellan den svenska välfärdsstaten och medborgarna bygger på att den som blir sjuk eller arbetslös får ta del av de tjänster 
och transfereringar de betalt för då de var yrkesverksamma. Om så inte sker finns det anledning att anta att tilltron till de socialpolitiska systemen minskar.

För grupper i marginalen finns det anledning att se med oro på tendenser till ökad återhållsamhet och striktare behovsprövning inom ramen för de system de berörs av. Ett exempel här är socialbidragen där det finns tydliga indikationer på en betydande åtstramning över tid, både när det gäller storleken på det bistånd som betalas ut och möjligheterna att få hjälp överhuvudtaget (se t.ex. Stranz 2007). Skärpta regler och förkortade ersättningsperioder för arbetslöshetsförsäkringen är avsedda att öka incitamenten för förvärvsarbete. Oavsett vilka effekter dessa förändringar har på kort eller lång sikt, kommer det alltid att finnas grupper för vilka steget ut i arbetslivet är längre och där incitamentsförstärkningar är jämförelsevis verkningslösa. Här finns det anledning att misstänka att levnadsvillkoren allvarligt försämras om inte alternativa stödformer utvecklas.

Inom ramen för detta temanummer är fokus huvudsakligen 2000-talets inledande år och övergången från krisåren till hur välfärden och välfärdens förutsättningar ser ut idag. Vi har valt att belysa de områden som är centrala för välfärd och ofärd idag. Vi menar dock att de teman som behandlas i de olika artiklarna genomgående behandlar välfärdspolitiskt centrala frågeställningar, med bäring också på kommande decennier.

\section{Temanumrets artiklar}

Som vi nämnde ovan slog 1990-talets kris också mot breda folklager. I stort sett alla demografiska och socioekonomiska grupper fick uppleva en försämrad välfärd under första halvan av 1990-talet. Trots det fanns det grupper vars ofärd ökade speciellt mycket nämligen invandrare, unga vuxna och ensamstående mödrar. Det är dessa grupper som är i fokus i artikeln "Vad hände med 1990-talets förlorargrupper" författad av Johan Fritzell, Michael Gähler och Magnus Nermo. Den övergripande frågan som ställs här är om dessa grupper fortsatt att halka efter eller om deras välfärd närmat sig befolkningen i stort. Resultaten pekar bl.a. på en ökad polarisering inom dessa grupper.

Socialbidragstagarna och då speciellt de med långvarigt socialbidragstagande kan i mångt och mycket ses som en grupp människor i samhällets marginaler. På så vis är omfattningen av det långvariga socialbidragstagandet en viktig indikator på förekomsten av ofärd. Med utgångspunkt från månadsbaserad statistik studerar Åke Bergmark och Olof Bäckman i sin artikel "Socialbidragstagandets dynamik" hur de tidsmässiga mönstren för bidragstagandet ser ut och vad som påverkar möjligheterna att bryta mer sammanhängande perioder med bidrag.

"Boendesegregationens utveckling och konsekvenser« är titeln på artikeln som skrivits av författarkonstellationen Maria Kölegård Stjärne, Johan Fritzell, Lars Brännström, Felipe Estrada och Anders Nilsson. En tilltagande boendesegregation ses av många som oförenlig med den generella välfärdspolitiken. Ändock är det, som författarna påpekar, inte så lätt att belägga hur individers välfärd påverkas av platsen där 
man bor. Med fokus på socioekonomisk segregation studeras här hur denna förändrats i 30 svenska städer, men i artikeln ges också exempel på bostadsområdesanalyser inom tre viktiga fält av välfärden: utsatthet för brott, hälsa och skolprestationer.

Den socialpolitiska fråga som kanske allra mest varit i fokus i debatten under 2000-talets inledande år rör sjukfrånvaron. Trots detta visar det sig att kunskaperna om sjukfrånvarons socioekonomiska fördelning är förvånansvärt begränsade. Olof Bäckman, Anna Bryngelson och Olle Lundbergs artikel „Den ojämlika sjukfrånvaron» söker råda bot på detta och fokuserar också på hur den socioekonomiska fördelningen av långtidssjukfrånvaro skiljer sig åt mellan kvinnor och män. Analyserna visar bl.a. att de klassmässiga skillnaderna i långvarig sjukskrivning tycks minska.

Välfärdsstatens åtaganden rör inte bara socialförsäkringar och bidragssystem. En viktig aspekt är också välfärdsstatens åtaganden när det gäller omsorg och service, det vi kallar välfärdstjänster. I artikeln, „Omsorgstjänster för äldre och funktionshindrade» gör Marta Szebehely och GunBritt Trydegård en systematisk jämförelse av trender och villkor inom äldre- och handikappomsorg under inledningen av 2000talet. Det visar sig att ekonomiska resurser, tjänsternas omfattning och personalens arbetsvillkor skiljer sig påtagligt mellan äldre- och handikappomsorgen, samtidigt som gränsen mellan statens, familjens och marknadens roller har förskjutits på olika sätt.

En ytterligare aspekt av välfärdsstaten rör förhållandena mellan den centrala statsapparaten och välfärdsstatens aktörer på mer lokal nivå. Också i dessa avseenden förändras tyngdpunkten över tid med viktiga konsekvenser för välfärd och sociala rättigheter. I artikeln »Decentraliserad välfärd eller medborgerliga rättigheter?» behandlar Åke Bergmark och Renate Minas de förskjutningar som skett härvidlag under de senaste decennierna. Genomgången visar bl.a. att staten, efter en lång period där decentraliserande beslut dominerat, återtagit initiativet på många områden i ingången av 2000-talet.

Sammantaget hoppas och tror vi att dessa axplock av centrala frågor för välfärd och socialpolitik skall väcka intresse. Den forskning som ligger till grund för artiklarna i detta temanummer har i huvudsak finansierats genom en rad olika individuella forskningsprojekt. Den övergripande finansieringen är emellertid ett långsiktigt programstöd från FAS (Johan Fritzell 2005 1697). Vi vill också passa på att rikta ett kollektivt tack till de redaktionsmedlemmar och kollegor som kritiskt och konstruktivt läst tidigare versioner av föreliggande artiklar. Vi vill också särskilt tacka GunBritt Trydegård som på en mängd olika sätt varit delaktig i planering och genomförande av arbetet med temanumret. 


\section{Referenser}

Batljan, I. \& Lagergren, M. (2005) „Future demand for formal long-term care in Sweden", European Journal of Ageing, 2, pp. 216-224.

Batljan, I. (2007) Demographics and Future Needs for Public Long Term Care and Services among the Eldely in Sweden. Avhandling. Stockholm: Stockholms Universitet, Institutionen för socialt arbete.

Fritzell, J. \& Lundberg, O. (2000) Välfärd, ofärd och ojämlikhet. SOU 2000:41. Stockholm: Fritzes.

Fritzell, J. (2001) »Inkomstfördelningens trender under 1990-talet». I J. Fritzell \& J. Palme (red.), Välfärdens finansiering och fördelning, SOU 2001:57. Stockholm: Fritzes.

Hinrichs, K. \& Kangas, O. (2003) "When is a change big enough to be a system shift? Small system-shifting changes in German and Finnish pension policies", Social Policy \& Administration, vol 37, pp. 573-9.
Institute for Futures Studies (2006) Sustainable Policies in an Ageing Europe. A Human Capital Response. Stockholm: Institute for Futures Studies.

Lundborg, P. (2000) „Vilka förlorade jobbet under 1990-talet?«. I J. Fritzell (2000) Välfärdens förutsättningar, SOU 2000:37. Stockholm: Fritzes.

Malmberg, B. \& Lindh, T. (2000) 40-talisternas uttåg - en ESO-rapport om 2000-talets demografiska utmaningar. Ds 2000:13. Stockholm: Finansdepartementet.

SOU 2001:79. Välfärdsbokslut för 1990-talet. Stockholm: Fritzes.

Stranz, H. (2007) Utrymme för variation - om prövning av socialbidrag. Avhandling. Stockholm: Stockholms Universitet, Institutionen för socialt arbete. 